\title{
Experiências Infantis e Risco de Abuso Físico: Mecanismos Envolvidos na Repetição da Violência
}

\author{
Child's Experiences and Risk of Physical Abuse: Mechanisms Involved \\ in Repeating Violence
}

\author{
Lilian Paula Degobbi Bérgamo* \& Marina Rezende Bazon \\ Universidade de São Paulo, Ribeirão Preto, Brasil
}

\begin{abstract}
Resumo
Este estudo verificou a transmissão geracional do abuso físico, investigando variáveis relacionadas às práticas educativas e de cuidados recebidas na infância e a qualidade de relacionamento com os pais em dois grupos, um formado por cuidadores notificados aos Conselhos Tutelares (G1) e outro sem histórico de violência contra os filhos (G2). Um percentual significativamente maior de G1 avaliou ter sofrido punição física na infância de forma mais grave e mais freqüente que G2, caracterizando abuso físico e/ou psicológico. Ademais, os participantes do G1 avaliaram sua relação com os responsáveis e o ambiente familiar no qual foram criados de modo mais negativo que G2. Os resultados permitiram descrever alguns mecanismos envolvidos na transmissão geracional da violência, oferecendo pistas para a prevenção.

Palavras-chave: Relações Familiares; Disciplina da Criança; Abuso Infantil; Transmissão Geracional; Aprendizagem/Apego.
\end{abstract}

\begin{abstract}
This study verified the generational transmission of physical abuse examining variables related to educative and care practices received during childhood and the relationship with the parents. Two groups were formed, one of parents notified by Child Protective Service Agencies for maltreatment (G1) and the other with no violence background against their children (G2), both were compared afterwards. An expressive percentage of G1 participants reported have received more severe physical punishment in the childhood and even more frequent than G2, which characterized the presence of psychological or physical abuse. Furthermore, G1 participants evaluated the relation with their parents and the family environment in which they were raised in a more negative way than G2 participants. The results enabled the illustration of some mechanisms involved in the generational transmission of violence, outlining some ways to prevent the problem.

Keywords: Family Relationships; Child Discipline; Child Abuse; Generational Transmission; Learning Process/Affection.
\end{abstract}

A violência física contra crianças, na família, encontra-se associada a uma gama de fatores que aumentam o risco de sua ocorrência. Um fator bastante investigado, em âmbito internacional, é a experiência de maus-tratos na própria infância dos cuidadores, colocando em pauta o tema da transmissão geracional da violência (DiLillo \& Damashek, 2003; Dixon, Browne, \& Hamilton-Giachritsis, 2005; Ertem, Leventhal, \& Dobbs, 2000; Pears \& Capaldi, 2001; Thompson, 2006).

A crença de que os indivíduos que sofreram abusos físicos em sua infância são mais propensos a abusar de

\footnotetext{
* Endereço para correspondência: Universidade de São Paulo, Faculdade de Filosofia Ciências e Letras, Departamento de Psicologia e Educação, Av. Bandeirantes, 3900, Monte Alegre, Ribeirão Preto, SP, Brasil, CEP 14040-901. E-mail: li.bergamo@pg.ffclrp.usp.br
}

seus próprios filhos é generalizada, apesar das evidências científicas demonstrarem que isto não é uma regra. As taxas de transmissão geracional giram em torno de apenas 30\% (Kaufman \& Zigler, 1987, 1989; Pears \& Capaldi, 2001), indicando que não há relação de determinação direta entre o fato de ter sido maltratado e o de vir a maltratar os próprios filhos. A relação entre as duas variáveis é, certamente, mediada por inúmeras outras, sendo que, ao longo do tempo, algumas aumentam as chances da transmissão da violência e outras minimizam (Crouch, Milner, \& Thomsen, 2001; McLewin \& Muller; 2006; Pears \& Capaldi, 2001).

Estudos buscaram identificar os mecanismos pelos quais o ciclo da violência é promovido, investigando os fatores que se somam à experiência infantil ou que a medeiam (Bower \& Knutson, 1996; Bower-Russa, 2005; Dixon et al., 2005; Pears \& Capaldi, 2001; Thompson, 
2006). Sabe-se que uma combinação da história de maustratos na infância com fatores de risco sócio-demográficos na vida adulta, como baixa renda, monoparentalidade, baixo nível educacional, e um destaque para maternidade/paternidade precoce, antes dos 21 anos, incrementam as chances de transmissão (Thompson, 2006). Em termos de mediação, estudos destacam os próprios efeitos dos maus-tratos no funcionamento psicológico do indivíduo, o qual teria maior probabilidade de apresentar algumas desordens, como depressão e ansiedade, que, por sua vez, se constituiriam em risco para o cometimento de maus-tratos infantis (Ateah \& Durrant, 2005; Thompson, 2006). Há também a possibilidade de a história de maustratos na infância, devido à exposição a modelos de relacionamento violento, concorrer para a escolha de um parceiro violento, dado que se mostra significativamente associado à utilização de práticas parentais fisicamente punitivas, o que per si aumenta as chances dos próprios descendentes sofrerem maus-tratos (Dixon et al., 2005; Gage \& Silvestre, 2010; Renner \& Slack, 2006; Thompson, 2006). Nesse contexto, ainda, a violência inter-conjugal também dificultaria o desenvolvimento de habilidades parentais de disciplina consistentes, gerando maior estresse na interação com a criança e incrementando o risco de maus-tratos dos filhos (Newcomb \& Locke, 2001; Pears \& Capaldi, 2001).

Em suma, de acordo com a literatura, a exposição a maus-tratos na infância pode produzir efeitos negativos por meio de diferentes mecanismos, sendo que todos tornariam o adulto mais vulnerável a estressores diversos, os quais, no contexto do exercício de sua própria parentalidade, funcionariam como riscos proximais para a repetição da violência com os próprios filhos (na ausência de mecanismos protetores).

Tratando especificamente dos abusos físicos, De Paúl e Domenech (2000) encontraram que mães que haviam sofrido punição física com a produção de danos físicos apresentavam um risco mais elevado de maltratar os filhos do que as que não haviam sofrido danos, indicando ser a severidade uma variável importante. Corroborando essa idéia, Pears e Capaldi (2001), além da severidade, constataram que a frequência da punição sofrida também seria um fator relevante na transmissão da violência de uma geração para outra.

Milner, Robertson e Rogers (1990), focalizando as percepções, demonstraram que o modo como o trauma físico é experimentado seria mais marcante do que os atos abusivos em si. A noção de merecimento da punição (ou do abuso físico sofrido) seria a base para o desenvolvimento de atitudes de aprovação do uso dessa, sendo uma das vias pela qual a história de punição influenciaria as estratégias disciplinares utilizadas com os filhos (Bower-Russa, 2005; Rodriguez \& Price, 2004). Bower e Knutson (1996), ao avaliar a relação entre a classificação das experiências vividas e o desenvolvimento de atitudes favoráveis à utilização da punição física com os próprios filhos, verificaram que se a experiência de ter sido punido na própria infância atrelava-se a ter sofrido danos severos, havia também algum nível de consciência das consequências negativas dessa, o que aumentava as chances dela ser classificada como abuso e de haver o desenvolvimento de atitudes negativas frente à sua utilização. Cogita-se, portanto, que se o cuidador consegue identificar as consequências físicas das experiências abusivas e o sofrimento associado, isso pode funcionar como fator de proteção para a repetição da violência. Por outro lado, se ele não é capaz ou não recebeu apoio suficiente para ser capaz de perceber a gravidade dos abusos sofridos, o risco de maltratar os próprios filhos será maior.

Nessa linha, tem-se verificado que sintomas associados ao quadro de "estresse pós-traumático" podem funcionar como mediadores da transmissão geracional da violência. A dissociação (definida como uma integração reduzida entre emoção, comportamento, memória e identidade) seria uma das explicações possíveis para a associação entre a história de abuso físico na infância e os maus-tratos com os descendentes, operando como um mecanismo que atuaria como defesa ao trauma sofrido na infância; persistindo, porém, a dissociação colocaria a pessoa em uma situação de alto risco para repetir a violência (Narang \& Contreras, 2005). Milner et al. (2010) encontraram que outros sintomas que caracterizam o quadro de "estresse pós-traumático" explicaram de 79\% a $90 \%$ a associação entre a experiência de abuso físico na infância e o risco de o adulto cometer este tipo de maustratos com os filhos, estudando amostras distintas.

Em âmbito nacional, não foram identificadas investigações específicas sobre a transmissão geracional da violência, dispondo-se mais propriamente de estudos focalizando a transmissão de estilos parentais através de diferentes gerações. E. A. Oliveira et al. (2002) encontraram que as mães que percebem suas experiências de criação pregressa como autoritárias relatam um estilo parental também autoritário com os próprios filhos, sendo que a transmissão teria sido mediada por relacionamento conjugal conflituoso. Weber, Selig, Bernardi e Salvador (2006) verificaram que houve transmissão geracional do estilo parental em $91,7 \%$ dos casos investigados. Dentre as dimensões avaliadas (comunicação negativa, punição inadequada, modelo, sentimento dos filhos, entre outras), em apenas três (relacionamento afetivo com a mãe, envolvimento, comunicação positiva dos filhos com a mãe) não se teria constatado a intergeracionalidade, o que foi relacionado a mudanças socioculturais que teriam interferido nos valores familiares ao longo do tempo.

Outros estudos nacionais abordam o tema da transmissão geracional da violência no contexto de uma discussão mais ampla. Oliveira-Formosinho e Araújo (2002) destacam que a transmissão seria moderada por algumas variáveis como o tipo de maus-tratos sofrido na infância, a qualidade das relações sociais estabelecidas pela vítima, os aspectos cognitivos e emocionais que a caracterizam, 
e os estressores que a afetaram durante a vida. Cecconello, De Antoni e Koller (2003), em um estudo de revisão sobre práticas e estilos parentais como fatores de risco ou proteção para o abuso físico, argumentam que indivíduos que foram criados por meio de práticas disciplinares coercitivas e até abusivas tendem a reproduzi-las com seus descendentes pela não exposição a modelos parentais competentes, segundo os princípios da aprendizagem social. T. T. S. S. Oliveira (2006), objetivando conhecer as concepções sobre práticas educativas e papel parental em um grupo de pais $(n=6)$ notificados por abusos físicos, identificou, à exceção de um, que todos teriam experienciado práticas educativas severas, como surras e castigos corporais, sugerindo a transmissão geracional da violência em algum grau, embora alerte sobre a importância de evitar pensar tal fenômeno de forma direta e linear.

Bordin, Paula, Nascimento e Duarte (2006), visando estimar a prevalência de punição física grave de crianças/adolescentes em comunidade de baixa renda e examinar problemas de saúde mental associados, verificaram que o grupo envolvido em tais práticas estava mais fortemente relacionado ao histórico de severas punições físicas na própria infância e que seus filhos apresentavam significativamente mais problemas de saúde mental. Baseando-se nesses resultados, Mendlowicz e Figueira (2007) hipotetizaram que os maus-tratos sofridos na infância constituem-se em traumas que repercutem no desenvolvimento psicológico do indivíduo a ponto de ocasionar déficits permanentes na regulação dos processos básicos requeridos para o desenvolvimento de habilidades parentais, o que aumentaria o risco da repetição dos maus-tratos.

Por tratar-se de um enfoque promissor para a compreensão dos mecanismos que subjazem o comportamento abusivo (Mendlowicz \& Figueira, 2007), oferecendo, portanto, pistas para o desenvolvimento de intervenções preventivas primárias e/ou secundárias, denota-se a necessidade de investir em pesquisas especificas sobre transmissão geracional da violência no contexto sóciocultural brasileiro. Assim, o presente estudo pretende contribuir neste cenário, buscando verificar a existência de relação entre o cometimento de abuso físico contra os filhos e aspectos da infância do abusador (especificamente, as práticas educativas e de cuidado às quais teria sido submetido e a percepção sobre a qualidade da relação com os pais, o clima emocional permeando a relação). Destaca-se que no tocante às práticas de punição corporal vivenciadas, as variáveis frequência e intensidade, foram consideradas para caracterizar a vivência de abuso na infância.

Tendo por referencial a Teoria da Aprendizagem Social (Bandura, 1977) e a do Apego (Bowlby, 1988), assume-se que o comportamento abusivo decorreria não só da aprendizagem direta, mas da aprendizagem de "uma filosofia de disciplina" e de modos de regulação da emoção, principalmente da agressividade/raiva, bem como da internalização de um modelo parental não-responsivo.
Nesse sentido, em acordo com a Teoria da Aprendizagem Social, preconiza-se que os comportamentos são aprendidos por observação e imitação daqueles apresentados por modelos e que, dessa forma, os indivíduos que são submetidos a maus-tratos na infância aprendem comportamentos característicos da interação abusiva e tendem a utilizá-los quando se tornam cuidadores (Milner et al., 2010). Segundo a Teoria do Apego, as expectativas sobre as relações interpessoais e a própria capacidade de responder adequadamente a essas relações tem base nas primeiras experiências interativas, sendo que, no caso de indivíduos maltratados na infância, a representação interna dessas interações ficaria fragilizada, dificultando a constituição de relações interpessoais satisfatórias no futuro (Morton \& Browne, 1998).

\section{Método}

\section{Participantes}

O delineamento adotado foi o de caso-controle retrospectivo, buscando-se comparar dois grupos quanto à percepção de aspectos da própria infância. Participaram do estudo 60 cuidadores: 30 constituíram o Grupo Clínico (G1) e 30 o Grupo Controle (G2).

Compuseram o G1 pais/responsáveis que haviam sido notificados aos Conselhos Tutelares da cidade de Ribeirão Preto - SP por mau-trato físico contra os filhos, sendo que a criança/adolescente, foco da notificação, deveria ter até quinze anos de idade (já que o abuso físico não ocorre com frequência em crianças mais velhas). Coletados os dados com o G1, as informações de natureza sócio-demográficas foram organizadas de modo a criar parâmetros para o recrutamento dos participantes do G2, visando emparelhar sujeito a sujeito. Assim, o G2 foi formado a partir de indicações de profissionais da área da assistência social do município, de adultos/responsáveis que residiam nas mesmas regiões e bairros que os do G1, mas que nas avaliações dos profissionais eram adequados nos cuidados despendidos aos filhos, e não possuíam histórico oficial de maus-tratos.

Considerando um $p<0,05$, os grupos equipararam-se em idade, sexo, escolaridade, nível sócio-econômico, situação conjugal, total de crianças sob seus cuidados e idade de um dos filhos (a criança em virtude da qual o cuidador teria sido notificado ao Conselho Tutelar). Os participantes do G1 tinham em média 34 anos, e os de G2 36 anos $(p=0,373), 20 \%(n=6)$ eram homens e $80 \%(n=$ 24) mulheres em ambos os grupos, $70 \%(n=21)$ possuíam companheiro(a) também em ambos os grupos, a escolaridade média era de 6,2 anos em G1 e 6,5 anos em $\mathrm{G} 2(p=0,765)$. Os participantes de $\mathrm{G} 1$ tinham em média 2,9 filhos com média de idade de 9,7 anos, em G2 o número médio de filhos era de 2,5 com média de idade de 9,2 anos ( $p=0,363$ e $p=0,603$ respectivamente). Em ambos os grupos, os participantes em média, pertenciam a classe $\mathrm{C}$, onde não se observou diferença significativa entre os grupos $(p=0,117)$. 
Tanto em G1 como em G2, 28 participantes (93,3\%) cresceram junto aos genitores, sendo que os demais foram criados por pais substitutos ou em abrigos. No entanto, no G1, 18 participantes $(64,2 \%)$ cresceram com ambos os pais biológicos e $10(35,7 \%)$ moraram com somente um deles, sendo que em 8 desses casos, o genitor constituiu uma nova família. Já no G2, 22 participantes $(78,6 \%)$ moraram com ambos os genitores, $5(17,8 \%)$ cresceram em famílias reconstituídas, e 1 (3,6\%) em família monoparental.

\section{Instrumentos}

Questionário de Caracterização Sócio-Demográfica. O qual obteve informações sobre idade, sexo, escolaridade, situação conjugal, número de filhos ou crianças sob os cuidados e idade dessas.

Critério de Classificação Econômica Brasil - CCEB (Associação Brasileira de Empresas de Pesquisa [ABEP], 2003). Check-list que verifica a posse de determinados bens de consumo e o grau de instrução do chefe da família, classificando-a em termos econômicos, em classes que vão de A1 a E.

Questionário "História da Infância do Adulto". Baseado no Maternal History Interview (MHI), instrumento elaborado por Altemeier et al. (citado por Bringiotti, 1999). Esse investiga as memórias dos adultos sobre sua infância no que tange à qualidade do relacionamento com os cuidadores e a identificação com esses e busca informações sobre as práticas de cuidado/educativas vividas. Segundo Bringiotti (1999), os resultados obtidos com esse instrumento têm permitido verificar uma relação entre características negativas da infância (como carência de afeto e de estabilidade, bem como práticas de maus-tratos físicos) e comportamentos de maus-tratos com os próprios filhos. Além disso, a autora refere que o instrumento apresenta um bom índice de fidedignidade, com coeficiente alpha de 0,9016. A versão aqui empregada foi traduzida do questionário em espanhol (Bringiotti, 2000), composto por onze perguntas; a essas foram acrescentadas outras sete, visando ampliar a investigação de aspectos relacionados aos cuidados e práticas disciplinares. A versão em português foi previamente testada em seis voluntários objetivando averiguar a compreensão das questões. Todas as questões forneciam opções de resposta que remetem a categorias que podem ser analisadas em termos de frequência e porcentagem.

\section{Procedimentos de Coleta e Análise dos Dados}

O levantamento dos casos que compuseram o G1 foi feito com base nos registros dos Conselhos Tutelares, focando-se naqueles que continham termos alusivos a mau-trato físico ("agressão", "violência", "espancamento"). Procedeu-se, então, à leitura das fichas que continham a descrição do acontecimento, selecionando-se 90 casos, dos quais 44 não foram localizados, 8 recusaramse a participar e 8 não foram contatados já que a amostra havia atingido o número pretendido de participantes $(n=30)$. Os dados do G1 foram coletados primeiro e, a partir de suas características sócio-demográficas, compôs-se o G2, conforme o anteriormente mencionado.

Os potenciais participantes foram contatados em suas residências, apresentando-lhes o Termo de Consentimento Livre e Esclarecido. Aos participantes do G1 apresentouse também uma carta que continha a autorização dos Conselhos Tutelares para contatá-los e ressaltava a desvinculação da pesquisa das práticas deste órgão. $\mathrm{Na}$ aplicação dos instrumentos utilizou-se o formato de hetero-aplicação, dado o baixo nível de escolaridade dos participantes.

As respostas fornecidas pelos participantes ao Questionário de Caracterização e ao Critério Brasil foram analisadas e convertidas em categorias numéricas, procedendo-se, em seguida, o cálculo de médias e desvios-padrão. As respostas fornecidas ao Questionário História da Infância do Adulto foram computadas por meio de frequências e porcentagens, sendo que para a análise comparativa entre os grupos utilizou-se o teste do $X^{2}$ (Qui-quadrado) ou o Exato de Fisher, adotando-se como nível de significância $p<0,05$. Quando houve diferença significativa foi calculado o odds ratio, com um intervalo de confiança (IC) de 95\%.

\section{Resultados}

Primeiramente, apresentam-se os resultados relativos à avaliação geral que os participantes fizeram da própria infância. No G1, 22 participantes $(73,3 \%)$ avaliaram-na como intermediária ou infeliz, e $8(26,6 \%)$ como feliz. No G2, ao contrário, 22 participantes $(73,3 \%)$ avaliaram a infância como feliz e 8 como intermediária ou infeliz.

Os resultados relativos às práticas de cuidados a que teriam sido submetidos indicam que o total de participantes do G1 (100\%) e 28 (93,3\%) do G2 relataram o recebimento de cuidados adequados de higiene e alimentação, sendo que 2 participantes $(6,7 \%)$ do G2 responderam a essa negativamente. No que se refere à saúde, novamente $100 \%$ dos participantes do G1 e $29(96,6 \%)$ do G2 indicaram ter recebido cuidados adequados. Questionados sobre o fato de serem deixados sozinhos em casa por longos períodos, durante a infância, a maioria de ambos os grupos, 19 (63,3\%) do G1 e 25 (83,3\%) do G2 responderam negativamente. No entanto, 11 participantes $(36,7 \%)$ do G1 e $5(16,7 \%)$ do G2 responderam afirmativamente, havendo uma tendência do G1 apresentar percentual superior ao G2. Para um IC de $95 \%(0,86-$ $9,75)$ o cálculo de odss ratio foi de 2,9 , estimando-se que os integrantes de G1 teriam 2,9 vezes mais chance de terem sido deixados sozinhos em casa.

Os resultados a seguir (Tabela 1) referem-se à distribuição e à comparação das respostas dos participantes quanto aos indicadores relacionados às práticas educativas às quais teriam sido submetidos. Destaca-se que a maioria dos participantes dos dois grupos, 29 (96,6\%) do G1 e 28 (93,3\%) do G2, relatou ter recebido alguma forma de punição. 
Tabela 1

Distribuição dos Participantes de Ambos os Grupos que eram Submetidos à Punição Física, quanto à Freqüência, Modo e Conseqüencias Associadas a essa Prática

\begin{tabular}{|c|c|c|c|c|c|}
\hline \multirow{2}{*}{ Grupo/resposta } & \multicolumn{2}{|c|}{ G1 } & \multicolumn{2}{|c|}{ G2 } & \multirow[b]{2}{*}{$p$} \\
\hline & $f$ & $\%$ & $f$ & $\%$ & \\
\hline Tipo de punição & $n=29$ & $n=28$ & & & \\
\hline Corporal/física & 24 & $82,7^{*}$ & 13 & 46,5 & 0,004 \\
\hline Não corporal & 5 & 17,3 & 15 & 53,5 & \\
\hline Freqüência & $n=24$ & $n=13$ & & & \\
\hline Apanhou algumas vezes & 9 & 37,4 & 9 & 69,2 & \\
\hline Apanhou muitas vezes & 15 & 62,5 & 4 & 30,8 & 0,07 \\
\hline \multicolumn{6}{|c|}{ Forma como a punição era aplicada } \\
\hline Por meio de palmadas & 4 & 16,7 & 8 & 61,5 & \\
\hline Emprego de objetos & 20 & $83,3^{*}$ & 5 & 38,5 & 0,01 \\
\hline \multicolumn{6}{|c|}{$\begin{array}{l}\text { Consequências (hematomas/marcas, } \\
\text { ferimentos e/ou fraturas) }\end{array}$} \\
\hline Sim & 12 & 50 & 2 & 15,4 & 0,07 \\
\hline Não & 12 & 50 & 11 & 84,6 & \\
\hline
\end{tabular}

$*_{p}<0,05$.

Quanto ao tipo de punição recebida, o G1 apresentou percentual significativamente superior a G2 no que se refere à punição corporal. Para um IC de $95 \%(1,64-18,70)$ o cálculo de odss ratio foi de 5,5, estimando-se que os integrantes de G1 teriam 5,5 vezes mais chance de ter experenciado punição física que os de G2. Com relação à frequência, houve uma tendência do percentual de participantes de G1 que teria apanhado muitas vezes ser superior ao do G2. Destaca-se também que o G1 apresentou percentual significativamente superior ao G2 quanto ao recebimento da punição corporal por meio de objetos. Para um IC de 95\% (1,70-37,7) o odss ratio foi de 8,0 estimando-se que G1 teria 8 vezes mais chance de ter sido punido fisicamente com o emprego de objetos que G2. Quanto às consequências das punições corporais sofridas, não houve diferença significativa entre os grupos, existindo, porém, uma forte tendência do percentual de sujeitos de G1 ser significantemente maior que o de G2 no que tange à ocorrência de algum tipo de conseqüência $(50,0 \%>15,4 \%)$.

Os participantes também foram questionados sobre se consideravam ou não as punições corporais sofridas como indevidas/injustas. A maioria do G1, 15 participantes $(62,5 \%)$ afirmaram que sim, e 9 participantes $(37,5 \%)$ que não. No G2, no entanto, 11 participantes $(84,6 \%)$ disseram que as punições recebidas foram devidas/justas, e $2(15,4 \%)$ disseram que foram injustas. O G1 apresentou percentual significativamente superior ao $\mathrm{G} 2(p=0,02)$ no que se refere à avaliação das punições como indevidas. Para um IC de $95 \%(1,64-51,12)$ o odss ratio foi de 9,17 , indicando que os integrantes de G1 teriam 9 vezes mais chance de considerarem as punições como inadequadas que os de G2.
A seguir, apresentam-se os resultados da distribuição dos participantes quanto às variáveis ligadas às práticas educativas de natureza não corporal, frisando-se que, embora 1 participante do G1 e 2 do G2 tenham, a priori, afirmado não terem sofrido punições, todos os participantes $(n=60)$ confirmaram terem "levado bronca" quando questionados. No entanto, quando questionados sobre a compreensão dessas broncas, 16 participantes $(53,3 \%)$ do G1 disseram que as compreendiam, e $14(46,7 \%)$ disseram que não, ao passo que em G2, $20(66,7 \%)$ responderam que sim e $10(33,3 \%)$ que não, não havendo diferença significativa entre os grupos.

Quanto à liberdade que sentiam para questionar os pais em suas opiniões, no G1 7 participantes $(23,3 \%)$ relataram que faziam isso, enquanto $23(76,7 \%)$ relataram que não. No G2, $16(53,3 \%)$ disseram que se sentiam à vontade para tal questionamento e $14(46,7 \%)$ disseram que não. Houve diferença entre os grupos $(p=0,02)$ no percentual de respostas negativas. Para um IC de $95 \%$ $(1,24-11,39)$ o odss ratio foi de 3,75 , estimando-se que G1 tem 3,7 vezes mais chance de não ter se sentido à vontade para questionar os pais que G2. Indagou-se ainda aos participantes se se percebiam ou não como alvo da raiva/nervosismo dos cuidadores, sendo que a maioria dos dois grupos respondeu negativamente. Porém, 13 participantes $(43,3 \%)$ do G1 e $6(20 \%)$ do G2 responderam afirmativamente, havendo diferença significativa entre os grupos $(p=0,05)$. Para um IC de $95 \%(0,97-9,66)$, o odss ratio foi igual a 3,06 , sendo que os participantes do G1 têm 3 vezes mais chance de se perceberem como tendo sido alvo da raiva dos pais.

Para aqueles que foram criados em famílias bi-parentais (de origem ou reconstituída), indagou-se sobre o fato de 
presenciarem ou não brigas do casal. Dos participantes do G1 $(n=26), 16(61,5 \%)$ responderam afirmativamente e $10(38,5 \%)$ negativamente. Dentre os participantes do G2 $(n=27), 9(33,3 \%)$ disseram ter presenciado brigas, e $18(66,7 \%)$ disseram que não. Houve diferença significativa entre os grupos $(p=0,04)$ no percentual de respostas positivas. Para um IC de 95\% (1,04-9,85), o odss ratio foi igual a 3,2, estimando-se que os integrantes de G1 teriam 3 vezes mais chance de ter presenciado brigas que os de G2.

Na Tabela 2, apresentam-se os resultados da distribuição das respostas dos participantes referentes às questões acerca de sua percepção e avaliação do relacionamento com as figuras parentais.

Tabela 2

Distribuição dos Participantes quanto à Percepção e à Avaliação do Relacionamento com os Cuidadores

\begin{tabular}{|c|c|c|c|c|c|}
\hline \multirow[t]{2}{*}{ Grupo/resposta } & \multicolumn{2}{|c|}{ G1 } & \multicolumn{2}{|c|}{$\mathrm{G} 2$} & \multirow[b]{2}{*}{$p$} \\
\hline & $f$ & $\%$ & $f$ & $\%$ & \\
\hline Relacionamento com a mãe & $n=30$ & & $n=29$ & & \\
\hline Próximo afetivamente & 22 & 73,3 & 28 & 96,6 & \\
\hline Afastados ou sem relacionamento & 8 & $26,7^{*}$ & 1 & 3,4 & 0,03 \\
\hline Qualidade do relacionamento com a mãe & $n=30$ & & $n=29$ & & \\
\hline Excelente/muito bom & 18 & 60 & 28 & 96,6 & \\
\hline Bom & 7 & 23,3 & 1 & 3,3 & \\
\hline Razoável & 4 & 13,3 & 0 & 0 & \\
\hline Ruim & 1 & 3,3 & 0 & 0 & \\
\hline Relacionamento com o pai & $n=28$ & & $n=28$ & & \\
\hline Próximo afetivamente & 16 & 57 & 23 & 82,1 & \\
\hline Afastados ou sem relacionamento & 12 & $43 *$ & 5 & 17,9 & 0,04 \\
\hline Qualidade do relacionamento com o pai & $n=28$ & & $n=28$ & & \\
\hline Excelente/muito bom & 15 & 53,6 & 19 & 67,9 & \\
\hline Bom & 3 & 10,7 & 8 & 28,5 & \\
\hline Razoável & 5 & 17,8 & 0 & 0 & \\
\hline Ruim & 5 & 17,8 & 1 & 3,5 & \\
\hline $\begin{array}{l}\text { Considera que foi amado pelos pais, } \\
\text { como uma criança deveria ser? }\end{array}$ & $n=30$ & & $n=30$ & & \\
\hline Sim, pelos dois pais & 11 & 36,7 & 23 & 76,6 & \\
\hline Sentiu-se amado por um dos pais & 7 & 23,3 & 3 & 10 & \\
\hline Sentiu-se amado parcialmente pelos dois & 8 & 26,6 & 4 & 13,3 & \\
\hline Não & 4 & 13,3 & 0 & 0 & \\
\hline
\end{tabular}

$*_{p}<0,05$.

Quanto à variável "relacionamento com a mãe", o percentual de sujeitos que se considerou afastado ou sem relacionamento com a mesma é maior no G1. Para um IC de $95 \%(1,18-90,90)$ o odss ratio foi igual a 10,2 , estimando-se que G1 tem dez vezes mais chance de ter experimentado um distanciamento da figura materna do que G2. Quanto ao "relacionamento com o pai", também o percentual afastado/sem relacionamento com esta figura foi maior no G1. Para um IC de 95\% (1,02-11,76), o cálculo de odss ratio foi igual a 3,45, estimando-se que o G1 tem 3,5 vezes mais chance de ter experimentado um distanciamento em relação à figura paterna do que G2. Os participantes também foram questionados a respeito de seu desejo de ser como seus pais (pai ou mãe). Neste sentido, verificou-se uma diferença significativa entre os grupos quanto à resposta " $n \tilde{a} o$ " $(p=0,02)$, sendo o percentual de G1 superior ao G2 $(50 \%>16,7 \%)$. Além disso, o percentual de G1 que afirmou estar disposto a reproduzir integralmente as mesmas práticas e atitudes dos pais/cuidadores com os próprios filhos foi inferior ao de G2 $(50 \%<83,3 \%)$.

\section{Discussão}

Com a presente investigação pretendeu-se verificar a relação entre aspectos da infância dos cuidadores e o cometimento de abuso físico contra os filhos, buscando-se evidências de vitimização doméstica dos próprios cuidadores quando crianças, visando elucidar alguns dos mecanismos envolvidos nesse ciclo de transmissão geracional do abuso físico infantil.

De modo geral, pode-se afirmar que a maioria dos participantes que constituíram o G1 referiu vivências infantis negativas, e que a comparação dos dois grupos 
os diferenciou em praticamente todas as variáveis estudadas, tanto nas relativas às práticas de cuidado $\mathrm{e}$ educativas, quanto nas relativas à qualidade do afeto no ambiente familiar e do relacionamento com seus pais/ cuidadores. Nessa direção, sobressai-se o fato da maioria dos participantes de G1 ter avaliado a própria infância como tendo sido intermediária ou infeliz, ao passo que no $\mathrm{G} 2$ a maioria a avaliou como feliz.

Retomando os resultados, ponto por ponto, outros aspectos merecem destaque. Primeiramente, há que se notar o fato da maior parte dos participantes, em ambos os grupos, avaliar positivamente os cuidados físicos recebidos quanto à higiene/saúde e à alimentação, indicando não haver uma vivência peculiar em G1 nesse plano. Entretanto, no que se refere às práticas educativas, salta aos olhos o fato da maioria de G1 ter sofrido punição de natureza corporal, sendo essas frequentes e severas e, geralmente, aplicada com o emprego de um objeto (como chinelos, cintas, varas, etc.), aspecto que, inclusive, os diferencia dos participantes do G2.

As situações de punição corporal devem ser caracterizadas como abusivas se forem excessivas e frequentes (abuso psicológico) e se aplicadas por meio de objetos (abuso físico), o que permite considerar que G1 teria sido mais exposto a práticas passíveis de serem classificadas como maus-tratos físico e/ou psicológico (Associação Brasileira Multiprofissional de Proteção à Infância e Adolescência [ABRAPIA], 2009; World Health Organization [WHO] \& International Society for Prevention of Child Abuse and Neglect [ISPCAN], 2006). Assim, num primeiro plano, dispõe-se de evidências sobre o fato da maioria de G1 ter sofrido abusos em sua própria infância, o que reforça a tese de haver transmissão geracional da violência, em função de um mecanismo pelo qual se tende a reproduzir com os próprios filhos as práticas às quais se foi submetido na infância (Bordin et al., 2006; Cecconello et al., 2003; Kaufman \& Zigler, 1989; Muller, Hunter, \& Stollak, 1995).

Quanto à existência de consequências notáveis decorrentes das punições recebidas (hematomas, ferimentos e/ou fraturas), os resultados não indicaram diferença significativa, embora metade dos participantes do G1, do total submetido a tais práticas, tenha afirmado ter tido tal experiência. Tal constatação, à luz de proposições como as de Bower e Knutson (1996), é bastante interessante, pois, segundo esses autores, a existência de danos severos aumentaria as chances das punições serem percebidas como abusivas o que, por sua vez, funcionaria como fator de proteção à transmissão do abuso devido ao desenvolvimento de atitudes negativas frente a essas. Em sentido oposto, o fato de as experiências abusivas não terem produzido consequências físicas particularmente notáveis em G1 dificultaria sua pronta classificação como tal, aumentando o risco de sua reprodução com os próprios filhos.

É preciso notar que embora em proporções diferentes, em ambos os grupos há os sujeitos que teriam e os que não teriam sido submetidos a práticas que podem ser classificadas como abusivas, confirmando as investigações que indicam ser o "histórico de maus-tratos na infância" uma variável de risco nem sempre presente para os pais/ cuidadores envolvidos com essa problemática (Crouch et al., 2001; Kaufman \& Zigler, 1987, 1989; McLewin \& Muller; 2006; Pears \& Capaldi, 2001). Tal constatação implica em pensar, de um lado, que para os sujeitos que não maltratam os próprios filhos (G2), mas que teriam sido eles mesmos maltratados na infância, fatores moderadores (de proteção) concorreram e concorrem para que o problema não se manifeste; por outro lado, para os sujeitos notificados por abuso (G1), mas que não teriam eles mesmos sido submetidos a práticas abusivas, outras variáveis concorreram e concorrem para a produção do problema.

Nesse raciocínio, ainda no plano ontogenético, denota-se que para G1 há mais indicadores de vivências negativas do ponto de vista afetivo/emocional, que parecem caracterizar suas infâncias e também distingui-los de G2. Numa primeira instância, nota-se que há mais participantes de G1 a afirmar que não teriam sido amados plenamente pelos cuidadores como uma criança deveria ser, sendo que uma proporção significativamente maior de G1 se sentiria emocionalmente afastada das figuras parentais, tendendo a avaliar o relacionamento com essas mais negativamente. Na ótica da Teoria do Apego, pode-se pensar tais informações como indicadores de maior distanciamento afetivo entre os integrantes de G1 e seus próprios pais/responsáveis, decorrentes de falhas na relação de apego, sendo que a transmissão dos maustratos repousaria sobre a internalização de um modelo parental não-responsivo e, portanto, pouco sensível aos sinais e necessidades da criança (Belsky, 1993; Morton \& Browne, 1998).

Ainda nessa direção, sublinha-se o fato de uma proporção significativamente maior de G1 em comparação a G2, avaliar ter sido deixada sozinha em casa quando criança, por longos períodos. Para além da inadequação da situação concreta de cuidado a que tal informação remete, dependentemente das circunstâncias envolvidas, a experiência infantil assim percebida parece indicar a vivência de certo abandono emocional e, por conseguinte, a experimentação de isolamento emocional (De Paúl \& Domenech, 2000). Segundo McLewin e Muller (2006), esse tipo de experiência seria suscetível de gerar dificuldades na pessoa para desenvolver e acionar recursos internos para lidar com situações estressantes, incluindo aí a criação dos próprios filhos, convertendo-se em risco para o cometimento dos abusos físicos.

Alinhando-se a isso, dispõe-se também dos resultados referentes à indagação feita aos participantes sobre o desejo de ser o mesmo tipo de pai/mãe que os que tiveram, no sentido de investigar sua identificação com as figuras parentais. Em G1, denotar-se-ia menor identificação na medida em que para esse grupo observou-se mais respostas negativas em proporção significativamente maior, 
o que indicaria uma maior fragilidade dos modelos parentais internalizados.

Numa segunda instância, destaca-se que a maioria dos integrantes de G1 relatou ter sido exposta, quando criança, a brigas entres os pais/cuidadores (em proporção significativamente maior que em G2), bem como ter sido alvo da raiva/nervosismo dos cuidadores (também em proporção significativamente maior) e, com base nos resultados relativos à percepção das punições de natureza não corporal, percebia pouca possibilidade de contra-argumentar os pais/responsáveis (também em proporção significativamente maior que em G2), denotando, para esse grupo, a dificuldade experienciada de diálogo como forma de solução de conflitos com as figuras de autoridade/parentais. Nesse contexto, G1 teria sido mais exposto a interações marcadas por demonstração de maior hostilidade, assim como pela ausência de estabilidade e reciprocidade (Cecconello et al., 2003; De Antoni, Barone, $\&$ Koller, 2007; E. A. Oliveira et al., 2002), propícias à aprendizagem de determinadas formas de regulação da emoção, bem como de determinadas práticas educativas, menos favorecedoras do desenvolvimento de habilidades parentais (Cia, Pereira, Del Prette, \& Del Prette, 2006) e, por isso, passíveis de constituírem um dos mecanismos implicados na transmissão geracional dos abusos.

Em conjunto, esses resultados parecem indicar que em G1, independentemente do fato de ter sido ou não submetido a abusos físicos e/ou psicológicos, os participantes parecem se distinguir também por terem vivido em um ambiente familiar mais adverso, regido por figuras de autoridade mais intransigentes/austeras, e permeado por mais tensão associada às relações interpessoais. De uma perspectiva desenvolvimental, crescer em um ambiente assim pode ter afetado o progresso do desenvolvimento e as habilidades pessoais desses indivíduos, de tal maneira que o efeito negativo acumulado pode ter sido levado à idade adulta, e contribuído para a perpetuação do ciclo de violência (Widom, 1995).

Recorrendo-se ao conceito de estilo parental autoritário, pelo qual as relações são permeadas por restrição de autonomia, desconsideração do ponto de vista da criança e uso de punições, sabe-se que esse é suscetível de impactar negativamente o desenvolvimento emocional do indivíduo, convertendo-se em risco para os abusos físicos, além de existir alta probabilidade da transmissão do estilo parental em si, por meio das diferentes gerações, conforme indicam estudos (Cecconello et al., 2003; E. A. Oliveira et al., 2002; Weber et al., 2006). Ademais, considerando que as experiências relacionais infantis podem também influenciar a capacidade posterior do indivíduo desenvolver novos recursos de busca e aproveitamento de apoio social/emocional e também de regular emoções negativas, devido a falhas na relação de apego (Cloitre, Stovall-McClough, Zorbas, \& Charuvastra, 2008), podese pensar que as experiências de G1, caracterizadas por maior nível de tensão e maior distanciamento emocional, teriam se convertido em risco para o abuso físico por meio de seu efeito negativo na percepção dos outros como fonte de apoio. Nesse sentido, há evidências de que baixos níveis de apoio recebidos desde cedo, frente às situações estressantes, se relacionariam diretamente à percepção de falta de apoio atual, variável essa inversamente relacionada ao potencial de risco de maltratar os próprios filhos (Bérgamo, 2007; Crouch et al., 2001).

Conciliando, então, os dados relativos às práticas educativas e às vivências sociais/emocionais na família, tem-se que os integrantes de G1 teriam sofrido mais situações de abuso na própria infância e/ou vivenciado mais interações negativas, o que parece se ligar à produção dos abusos físicos contra os próprios filhos, em virtude da aprendizagem dos comportamentos abusivos (devido à exposição a modelos com essas características) e/ou devido a não aprendizagem de comportamentos apropriados (devido a não exposição a modelos competentes), bem como pelas dificuldades relacionadas à regulação da emoção e ao acionamento e aproveitamento de apoio social/emocional necessários para lidar com situações de estresse (e, dentro disso, desempenhar adequadamente o papel parental).

Por fim, vale notar que a indagação sobre a adequação das punições sofridas na infância revelou que a maioria de G1 as considerou como indevidas ou injustas, contradizendo a noção de merecimento que se constituiria em variável mediadora da reprodução de comportamentos abusivos (Rodriguez \& Price, 2004). Tais resultados indicam que G1 avaliaria mais negativamente as práticas educativas às quais teria sido submetido, o que remete, então, à indagação do porquê e como haveria reprodução dessas com os próprios filhos. Tais resultados embora permitam vislumbrar a existência de críticas às práticas educativas e à qualidade de relacionamento estabelecido com as figuras parentais, não permitem fazer qualquer assertiva sobre o fato das vivências serem percebidas por G1 como abusivas, o que, conforme o anteriormente mencionado, seria um elemento fundamental para a interrupção do ciclo de violência (Bower \& Knutson, 1996; Bower-Russa, 2005). Esse aspecto de críticas às figuras parentais, em G1, parece revelar mais propriamente uma menor identificação com essas figuras (ou um maior distanciamento afetivo), e também indicar que as experiências infantis associadas à criação/educação recebidas encontram-se permeadas por uma emoção negativa, de desconforto, de descontentamento. Nessa linha, ter-se-ia indivíduos padecendo de um alto grau de dissociação, que teria funcionado como proteção durante a própria infância, mas, na atualidade, concorreria para aumentar o risco de abuso dos próprios filhos (Milner et al., 2010; Narang \& Contreras, 2005), devido às inconsistências existentes entre as concepções a respeito do que seria idealmente o papel parental a ser desempenhado e aquilo que sabem e conseguem de fato fazer com os filhos, no cotidiano. 


\section{Considerações Finais}

O estudo aqui apresentado demonstrou a relação de diversas variáveis da infância do cuidador com o abuso físico contra os próprios filhos, permitindo constatar que o problema dos maus-tratos tende a ter continuidade de uma geração à outra e que certas variáveis parecem desempenhar nesse processo, um papel de mediação, contribuindo para se pensar aspectos essenciais ligados à prevenção do problema. $\mathrm{O}$ delineamento metodológico empregado (do tipo caso-controle) é bastante indicado para a investigação do problema da transmissão geracional dos maus-tratos, já que possibilita o controle de certas variáveis sócio-demográficas atuais, que poderiam interferir nos resultados obtidos (Ertem et al., 2000). No entanto, um dos limites refere-se à abordagem metodológica retrospectiva adotada, devido aos eventuais problemas de interferência das memórias dos participantes na qualidade dos dados obtidos (Ertem et al., 2000). Todavia, deve-se considerar que o instrumento de coleta utilizado apóia-se justamente nesse conceito, pressupondo que as vivências infantis têm impacto no presente em virtude da forma como são lembradas, o que, de algum modo, transforma o limite em força. Por fim, acredita-se que as pistas oferecidas pelo presente estudo devem ser colocadas à prova em outras pesquisas utilizando amostras mais numerosas e representativas da população, bem como diferentes modalidades de maus-tratos.

\section{Referências}

Associação Brasileira de Empresas de Pesquisa. (2003). Critério de Classificação Econômica Brasil. Retrieved January, 2006, from www.abep.org

Associação Brasileira Multiprofissional de Proteção à Infância e Adolescência. (2009). Violência: Física, Psicológica. Retrieved September, 2009, from www.observatoriodainfancia.com.br

Ateah, C. A., \& Durrant, J. E. (2005). Maternal use of physical punishment in response to child misbehavior: Implications for child abuse prevention. Child Abuse \& Neglect, 29,169-185.

Bandura, A. (1977). Social Learning Theory. New York: General Learning Press.

Belsky, J. (1993). Etiology of child maltreatment: A developmental-ecological analysis. Psychological Bulletin, 114, 413434.

Bérgamo, L. P. D. (2007). Maus-tratos físicos de crianças: Contribuições para a avaliação de fatores de risco psicossociais. Dissertação de Mestrado não-publicada, Departamento de Psicologia e Educação, Universidade de São Paulo, Ribeirão Preto, SP.

Bordin, I. A. S., Paula, C. S., Nascimento, R., \& Duarte, C. S. (2006). Severe physical punishment and mental health problems in economically disadvantaged population of children and adolescents. Revista Brasileira de Psiquiatria, 28(4), 290296.

Bower, M. E., \& Knutson, J. F. (1996). Attitudes toward physical discipline as function of disciplinary history and self-labeling as physically abused. Child Abuse \& Neglect, 20, 89-99.
Bower-Russa, M. (2005). Attitudes mediate the association between childhood disciplinary history and disciplinary responses. Child Maltreatment, 10, 272-282.

Bowlby, J. (1988). A secure base: Parent-child attachment and healthy human development. New York: Basic Books.

Bringiotti, M. I. (1999). Maltrato infantil. Factores de riesgo para el maltrato físico en la población infantil que concurre a las escuelas dependientes del Gobierno de la Ciudad de Buenos Aires. Buenos Aires, Argentina: Miño y Dávila.

Bringiotti, M. I. (2000). La escuela ante los niños maltratados. Buenos Aires, Argentina: Paídos.

Cecconello, A. M., De Antoni, C., \& Koller, S. H. (2003). Práticas educativas, estilos parentais e abuso físico no contexto familiar. Psicologia em Estudo, 8, 45-54.

Cia, F., Pereira, C. S., Del Prette, Z. A. P., \& Del Prette, A. (2006). Habilidades sociais parentais e o relacionamento entre pais e filhos. Psicologia em Estudo, 11(1), 73-81.

Cloitre, M., Stovall-McClough, C., Zorbas, P., \& Charuvastra, A. (2008). Attachment organization, emotion regulation, and expectations of support in a clinical sample of women with childhood abuse histories. Journal of Traumatic Stress, 21(3), 282-289.

Crouch, J. L., Milner, J. S., \& Thomsen, C. (2001). Childhood physical abuse, early social support, and risk for maltreatment: Current social support as a mediator of risk for child physical abuse. Child Abuse \& Neglect, 25, 93-107.

De Antoni, C., Barone, L. R., \& Koller, S. H. (2007). Indicadores de risco e proteção em famílias fisicamente abusivas. Psicologia: Teoria e Pesquisa, 23(2), 125-132.

De Paúl, J., \& Domenech, L. (2000). Childhood history of abuse and child abuse potential in adolescent mothers: A longitudinal study. Child Abuse \& Neglect, 24(5), 701-713.

DiLillo, D., \& Damashek, A. (2003). Parenting characteristics of women reporting a history of childhood sexual abuse. Child Maltreatment, 8, 319-333.

Dixon, L., Browne, K., \& Hamilton-Giachritsis, C. (2005). Risk factors of parents abused as children: A mediational analysis of the intergenerational continuity of childmaltreatment (Part I). Journal of Child Psychology and Psychiatry, 46(1), 47-57.

Ertem, L. O., Leventhal, J. M., \& Dobbs, S. (2000). Intergenerational continuity of child physical abuse: How good is the evidence? Lancet, 356, 814-819.

Gage, A. J., \& Silvestre, E. A. (2010). Maternal violence, victimization, and child physical punishment in Peru. Child Abuse \& Neglect, 34, 523-533.

Kaufman, J., \& Zigler, E. (1987). Do abused children become abusive parents? American Journal of Orthopsychiatry, 57, 186-192.

Kaufman, J., \& Zigler, E. (1989). The intergenerational transmission of child abuse. In D. Cicchetti (Ed.), Child maltreatment (pp. 129-150). New York: Cambridge University.

McLewin, L. A., \& Muller, R. T. (2006). Attachment and social support in the prediction of psychopathology among young adults with and without a history of physical maltreatment. Child Abuse \& Neglect, 30, 171-191.

Mendlowicz, M., \& Figueira, I. (2007). Transmissão Intergeracional da violência familiar: O papel do transtorno de estresse pós-traumático. Revista Brasileira de Psiquiatria, 29(1), 88-89.

Milner, J. S., Robertson, K. R., \& Rogers, D. L. (1990). Childhood history of abuse and adult child abuse potential. Journal of Family Violence, 5(1), 15-34. 
Milner, J. S., Thomsen, C. J., Crouch, J. L., Rabenhorst, M. M., Martens, P. M., Dyslin, C. W., et al. (2010). Do trauma symptoms mediate the relationship between childhood physical abuse and adult child abuse risk? Child Abuse \& Neglect, 34, 332-344.

Morton, N., \& Browne, K. D. (1998). Theory and observation of attachment and its relation to child maltreatment: A review. Child Abuse \& Neglect, 22(11), 1093-1104.

Muller, R. T., Hunter, J. E., \& Stollak, G. (1995). The intergenerational transmission of corporal punishment: A comparison of social learning and temperament models. Child Abuse \& Neglect, 19, 1323-1335.

Narang, D. S., \& Contreras, J. M. (2005).The relationships of dissociation and affective family environment with the intergenerational cycle of abuse. Child Abuse \& Neglect, 29, 683-699.

Newcomb, M. D., \& Locke, T. F. (2001). Intergenerational cycle of maltreatment: A popular concept obscured by methodological limitations. Child Abuse \& Neglect, 25, 1219-1240.

Oliveira, E. A., Marin, A. H., Pires, F. B., Frizzo, G. B., Ravanello, T., \& Rossato, C. (2002). Estilos parentais autoritário e democrático-recíproco intergeracionais, conflito conjugal e comportamentos de externalização e internalização. Psicologia: Reflexão e Crítica, 15(1),1-11.

Oliveira, T. T. S. S. (2006). Educar é punir? Compreendendo pontos de vistas de pais denunciados por violência física contra seus filhos. Dissertação de Mestrado não-publicada, Departamento de Psicologia e Educação, Universidade de São Paulo, Ribeirão Preto, SP.

Oliveira-Formosinho, J., \& Araújo, S. B. (2002). Entre o risco biológico e o risco social: Um estudo de caso. Educação e Pesquisa, 28(2), 87-103.

Pears, K. C., \& Capaldi, D. M. (2001). Intergenerational transmission of abuse: A two-generational prospective study of an at-risk sample. Child Abuse \& Neglect, 25, 1439-1461.

Renner, L. M., \& Slack, K. S. (2006). Intimate partner violence and child maltreatment: Understanding intra- and intergenerational connections. Child Abuse \& Neglect, 30, 599-617.

Rodriguez, C. M., \& Price, B. L. (2004). Attributions and discipline history as predictors of child abuse potential and future discipline practices. Child Abuse \& Neglect, 28, 845-861.

Thompson, R. (2006). Exploring the link between maternal history of childhood victimization and child risk of maltreatment. Journal of Trauma Practice, 5(2), 57-72.

Weber, L. N. D., Selig, G. A., Bernardi, M. G., \& Salvador, A. P. V. (2006). Continuidade dos estilos parentais através das gerações: Transmissão intergeracional de estilos parentais. Paidéia, 16(35), 407-414.

Widom, C. S. (1995). The cycle of violence. In J. D. Finkelman, Child abuse a ultidisciplinary survey short-and long-term effects (pp. 154-159). New York: Garland.

World Health Organization, \& International Society for Prevention of Child Abuse and Neglect. (2006). Preventing child maltreatment: A guide to taking action and generating evidence. Geneva, Switzerland: World Health Organization Press. 